\title{
Environmental Exposure of Sperm Sex-Chromosomes: A Gender Selection Technique
}

\author{
Ibukun P. Oyeyipo ${ }^{1,2}$, Michelle van der Linde ${ }^{1}$ and Stefan S. du Plessis ${ }^{1}$ \\ ${ }^{1}$ Division of Medical Physiology, Faculty of Medicine and Health Sciences, Stellenbosch University, Tygerberg, South Africa \\ ${ }^{2}$ Department of Physiology, College of Health Sciences, Osun State University, Osogbo, Osun State, Nigeria
}

\begin{abstract}
Preconceptual sex selection is still a highly debatable process whereby $\mathrm{X}$ - and Y-chromosome-bearing spermatozoa are isolated prior to fertilization of the oocyte. Although various separation techniques are available, none can guarantee $100 \%$ accuracy. The aim of this study was to separate X-and Y-chromosome-bearing spermatozoa using methods based on the viability difference between the X- and Y-chromosome-bearing spermatozoa. A total of 18 experimental semen samples were used, written consent was obtained from all donors and results were analysed in a blinded fashion. Spermatozoa were exposed to different $\mathrm{pH}$ values $(5.5,6.5,7.5,8.5$, and 9.5$)$, increased temperatures $\left(37^{\circ} \mathrm{C}, 41^{\circ} \mathrm{C}\right.$, and $\left.45^{\circ} \mathrm{C}\right)$ and ROS level $(50 \mu \mathrm{M}, 750 \mu \mathrm{M}$, and $1,000 \mu \mathrm{M})$. The live and dead cell separation was done through a modified swim-up technique. Changes in the sex-chromosome ratio of samples were established by double-label fluorescent in situ hybridization (FISH) before and after processing. The results indicated successful enrichment of Xchromosome-bearing spermatozoa upon incubation in acidic media, increased temperatures, and elevated $\mathrm{H}_{2} \mathrm{O}_{2}$. This study demonstrated the potential role for exploring the physiological differences between Xand Y-chromosome-bearing spermatozoa in the development of preconceptual gender selection.
\end{abstract}

Keywords: Sex-chromosomes, Motility, Velocity, Temperature, Hydrogen peroxide, Human

\section{INTRODUCTION}

The potential capacity to choose the sex of a child has intrigued many generations of parents. Sex selection can be accomplished by either applying advanced assisted reproduction techniques (ARTs), conducing preimplantation genetic diagnosis (PGD), or using cell sorting prior to fertilization. In addition, it can also be achieved through natural concep-

Correspondence to: Stefan S. du Plessis, Division of Medical Physiology, Faculty of Medicine and Health Sciences, Stellenbosch University, Francie van Zijl Drive, Tygerberg 7505, South Africa Email: ssdp@sun.ac.za

List of abbreviations: ANOVA, analysis of variance; ARTs, advanced assisted reproduction techniques; BSA, bovine serum albumin; PBS, phosphate buffer saline; LIN, linearity; PGD, preimplantation genetic diagnosis; SEM, standard error of the mean; STR, straightness; SURRG, Stellenbosch University Reproductive Research Group; VAP, average path velocity; VCL, curvilinear velocity; VSL, straight line velocity; WHO, World Health Organization.

This is an Open-Access article distributed under the terms of the Creative Commons Attribution Non-Commercial License (http:// creativecommons.org/licenses/by-nc/3.0) which permits unrestricted non-commercial use, distribution, and reproduction in any medium, provided the original work is properly cited. tion, although this option is not well-established yet and therefore, remains quite speculative. However, influencing the timing of fertilization with regard to ovulation is one of the natural methods believed to be effective, while PGD is very costly, highly invasive, and involves associated risks, as well as ethical issues (1). Sex selection through timely intercourse is based on the respective characteristics of the $\mathrm{X}$ - and Y-chromosome-bearing spermatozoa, favoring one or the other toward reaching and fertilizing the egg (2).

The ethicality of sex selection remains an unsettled and controversial topic; some countries allow gender selection for medical purposes, while others prohibit any form of sex selection $(3,4)$. Nonetheless, it is documented that many families, regardless of their culture or religion, prefer to practice gender selection to balance the family gender distribution (5). Circumventing the ethical issues implies that gender selection must be practiced prior to fertilization. Successful separation of $\mathrm{X}$ - and Y-chromosome-bearing spermatozoa could have great potential, as it could drastically lower the abortion, infanticide, and abandonment statistics of many countries; hence, there is a need for the development of ethical, cost effective, and successful methods toward sex selection. To achieve this goal, it is believed 
that combining sperm selection with Shettle's or Whelan's methods for the timing of fertilization with regard to ovulation would result in highly increased chances of successful preconceptual sex selection (6).

Many differences exist between X- and Y-chromosomebearing spermatozoa, including DNA content, size and density, motility, and surface protein properties (7-9). X-chromosome-bearing spermatozoa have been shown to contain $2.9 \%$ more DNA than Y-chromosome ones (10). Studies have also shown that Y-chromosome-bearing spermatozoa swim faster and more progressively than the X-chromosome ones (6). Y-chromosome-bearing spermatozoa have been shown to have a shorter lifespan, and cannot withstand exposure to acidic environments or oxidative stress for a very long period of time (8). They are also generally considered to be the most fragile among both types of spermatozoa. Cui and Matthews concluded that the length, perimeter, and area of the spermatozoa's heads, as well as the lengths of the neck region and tail were significantly larger and longer in X-chromosome-bearing spermatozoa than in Y-chromosome ones. Their study demonstrated that $\mathrm{X}$-chromosome-bearing spermatozoa are statistically larger than Y-chromosome ones (11).

It has been previously reported that many sperm separation methods have inconsistent results, and for this reason, none of these techniques have gained true acceptance within the scientific community (12). Therefore, there is still a need for the development of clinically significant and recognized techniques toward a successful natural strategy for sorting X- and Y-chromosome-bearing spermatozoa. In this regard, toxicity tests have been proven useful in reproduction (13) and more specifically, spermatozoa, which are specialized cells, have been reported to be highly sensitive to environmental factors such as temperature and redox state $(14,15)$. Although various studies have reported several morphological and functional differences between $\mathrm{X}$ and Y-chromosome-bearing spermatozoa, none of them have proven that these differences are significant enough to allow for the natural separation of spermatozoa into two populations based on these differences. Therefore, the aim of this study was to separate X- and Y-chromosome-bearing spermatozoa through methods based on their resilience toward exposure to wide ranges of $\mathrm{pH}$, temperature, and $\mathrm{H}_{2} \mathrm{O}_{2}$ concentration.

\section{MATERIALS AND METHODS}

Semen sampling. A total of 18 semen samples were obtained from healthy volunteers (19 26 years old) taking part in the Stellenbosch University reproductive research group (SURRG) donor program. All the donors were informed that their spermatozoa would be used exclusively for research purposes and discarded in an appropriate fashion, after which they gave their consent. Ethical clearance for this study was granted by the Health Research Ethics Committee 1 (Ethics \#: S13/04/068). Semen was collected from healthy donors according to the World Health Organization (WHO) guidelines (16). In each instance, the semen was allowed to undergo liquefaction $\left(30 \mathrm{~min} ; 37^{\circ} \mathrm{C}, 95 \%\right.$ humidity; $5 \% \mathrm{CO}_{2}$ ). The exclusion criteria used in this study were history of smoking and/or illicit drug use, exposure to any occupational or environmental toxicants, and use of medication. All semen samples included in the study had to conform to normality according to the WHO standards. Samples that did not comply were excluded from the study.

Sperm preparation. A 3\% HAMS-BSA solution was prepared by adding $0.3 \mathrm{~g}$ of bovine serum albumin (BSA) (Sigma-Aldrich, South Africa) to $10 \mathrm{~mL}$ of HAMS-F10 (Sigma-Aldrich). Two hundred microliters of semen were used for sex-chromosome ratio determination, the remaining semen was transferred to a conical tube, and $2 \mathrm{~mL}$ of HAMS-BSA solution was added. The concentrations, motility parameters, and viability percentages of the spermatozoa were determined after the preparation step, and used to indicate sperm parameters at time 0 .

Fluorescent in situ hybridization (FISH). The ratio of $\mathrm{X}$ - to Y-chromosome-bearing spermatozoa was determined with 2 color-fluorescent in situ hybridization. This process was performed on the neat sample to establish the natural unchanged sperm sex-chromosome ratio (i.e. before exposure), and on the various samples obtained after exposure to the different environments. The FISH protocol was used as specified by the manufacturer's instructions (Aczon, Nano Bio Tech, Italy). Briefly, DNA was decondensed and denatured into single strands and slides prepared. The singlestranded DNA was probed with short fluorescence-tagged oligonucleotides that were complementary to regions specific to either the $\mathrm{X}$ or $\mathrm{Y}$ chromosomes. The slides were then incubated in the dye overnight, mounted, and subsequently viewed under a fluorescent microscope. Manual assessment was performed and at least 200 cells were counted.

Incubation at varying $\mathbf{p H}$. Phosphate buffer saline (PBS) (Gibco, Scotland, UK) was used as the incubation medium and $\mathrm{pH}$ was adjusted to the targeted values of 5.5, 6.5, 7.5, 8.5 , and 9.5 with $1 \mathrm{M} \mathrm{NaCl}$ or $1 \mathrm{M} \mathrm{HCl}$. Fresh solutions were prepared prior to each experiment. After processing, the pellet was re-suspended in $1.2 \mathrm{~mL}$ of HAMS-BSA solution. A $200-\mu \mathrm{L}$ volume of the prepared spermatozoa was then added into each $\mathrm{pH}$ solution. After ensuring that the $\mathrm{pH}$ remained stable, sample tubes were incubated for $15 \mathrm{~min}$ $\left(37^{\circ} \mathrm{C}, 95 \%\right.$ humidity; $\left.5 \% \mathrm{CO}_{2}\right)$. Two hundred microliters of sample were used to establish the sperm concentration, motility parameters, and percentage viability at time 0 . After incubation, samples were re-assessed for motility and viability parameters. Live cell fractions were isolated by modi- 
fied swim-up, and the fractions were subsequently stored in liquid nitrogen $\left(-196^{\circ} \mathrm{C}\right)$ until FISH analysis.

Incubation at varying temperature. The prepared spermatozoa were divided into 3 aliquots and incubated at $37^{\circ} \mathrm{C}, 41^{\circ} \mathrm{C}$, and $45^{\circ} \mathrm{C}$ for $25 \mathrm{~min}$. After the incubation period, the live cell fractions were isolated using the modified swimup protocol, and subsequently stored in liquid nitrogen until further sex-chromosome determination.

Incubation at varying concentrations of hydrogen peroxide. $\mathrm{H}_{2} \mathrm{O}_{2}$ (Sigma-Aldrich, $30 \%\left(\mathrm{w} / \mathrm{w}\right.$ ) in $\mathrm{H}_{2} \mathrm{O}$ ) was diluted with PBS to yield final concentrations of $2,000 \mu \mathrm{M}$, $1,500 \mu \mathrm{M}$, or $100 \mu \mathrm{M}$. Fresh solutions were prepared daily in order to maintain the integrity of the incubation medium. After processing, the spermatozoa pellet was re-suspended in $1.2 \mathrm{~mL}$ HAMS-BSA. A $250-\mu \mathrm{L}$ volume of the prepared spermatozoa was added to $250 \mu \mathrm{L}$ of each of the $\mathrm{H}_{2} \mathrm{O}_{2}$ solutions, to give final stimulation concentrations of $1,000 \mu \mathrm{M}$, $750 \mu \mathrm{M}$, or $50 \mu \mathrm{M}$. A control solution consisting of $250 \mu \mathrm{L}$ spermatozoa mixed with $250 \mu \mathrm{L}$ PBS was also included. The remaining $200 \mu \mathrm{L}$ was used to establish the baseline concentration of the spermatozoa. The solutions were placed in the incubator $\left(37^{\circ} \mathrm{C}, 95 \%\right.$ humidity; $\left.5 \% \mathrm{CO}_{2}\right)$ for $25 \mathrm{~min}$, after which live cell fractions were isolated by modified swim-up protocols. These fractions were then stored in liquid nitrogen until the FISH procedure could be performed to determine sex-chromosome ratios.

\section{Semen Analysis.}

- Motility: The sperm concentration and motility in each sample were measured prior to the experiment in order to establish normality and baseline values of the sample, and thereafter at various time points throughout each experiment. Sperm concentration and motility were assessed by means of Computer Aided Sperm Analysis (CASA), using the Sperm Class Analyzer (SCA) (Microptics, Barcelona, Spain). Several motility parameters were assessed, including total motility (\%) and progressive motility (\%). Velocity parameters that were measured included curvilinear velocity (VCL) $(\mu \mathrm{m} / \mathrm{s})$, straight line velocity (VSL) $(\mu \mathrm{m} / \mathrm{s})$, average path velocity (VAP) $(\mu \mathrm{m} / \mathrm{s})$, linearity (LIN) $(\%)$, and straightness (STR) (\%).

- Modified Swim-up protocol: After the incubation period, the spermatozoa solutions were transferred into a new conical tube. HAMS-BSA $(1 \mathrm{~mL})$ was layered carefully on top of the sample, preventing mixing of the solutions. The tube was placed in the incubator at a $45^{\circ}$ angle for $25 \mathrm{~min}$, after which the top $500 \mu \mathrm{L}$ was carefully removed and the rest discarded. Motility, viability, and sexchromosome ratios were then assessed.

- Sub-zero storage: After swim-up processing, all samples were frozen in PBS without cryomedium in liquid nitrogen $\left(-196^{\circ} \mathrm{C}\right)$ and stored. Once all the samples had been collected, they were thawed at room temperature $(20 \mathrm{~min})$, appropriately pooled, and sex-chromosome determination was performed via FISH.

- Statistical analysis: Data were presented as mean \pm standard error of the mean (SEM) and were analyzed using one-way analysis of variance (ANOVA). Differences displaying $p<0.05$ were considered statistically significant. FISH data are presented in terms of ratio increase or decrease in absolute percentage difference.

\section{RESULTS}

\section{Effect of pH on spermatozoa.}

- Sex-chromosome ratio: The effect of $\mathrm{pH}$ on the sexchromosome ratios of the samples, expressed as the absolute changes in the incidence of sex-chromosomes compared to the original values, is shown in Fig. 1. After the 15-min incubation period, there was no change in the $\mathrm{X}: \mathrm{Y}$ sex-chromosome ratio measured in the neat sample at neutral $\mathrm{pH}(7.5)(55 \%: 45 \%)$. When compared to the sex-chromosome ratio measured in the neat sample, a very acidic $\mathrm{pH}$ (5.5) led to a considerable enrichment in X-chromosome-bearing spermatozoa, increasing from 55 to $62 \%$, ( $12.7 \%$ increase). However, the number of Y-chromosomebearing spermatozoa was enhanced in all the remaining samples compared to the neat semen sample, showing percentage increases of $8.9 \%$ ( $45 \%$ vs. $49 \%), 4.4 \%$ ( $45 \%$ vs. $47 \%)$, and $8.9 \%(45 \%$ vs. $49 \%)$ at $\mathrm{pH} 6.5,8.5$, and 9.5 , respectively, as shown in Fig. 1 and Table 1.

- Sperm motility: Fig. 2A and 2B illustrate the effect of incubation at various $\mathrm{pH}$ on the percentage of total and progressively motile spermatozoa in the samples, respectively. The lowest total and progressive motilities were observed at $\mathrm{pH} 5.5$, while increases in total and progressive motilities were observed at $\mathrm{pH} 9.5$.

- Sperm velocity parameters: The effect of $\mathrm{pH}$ on the velocity parameters (VCL, VSL, LIN, and STR) of the sper-

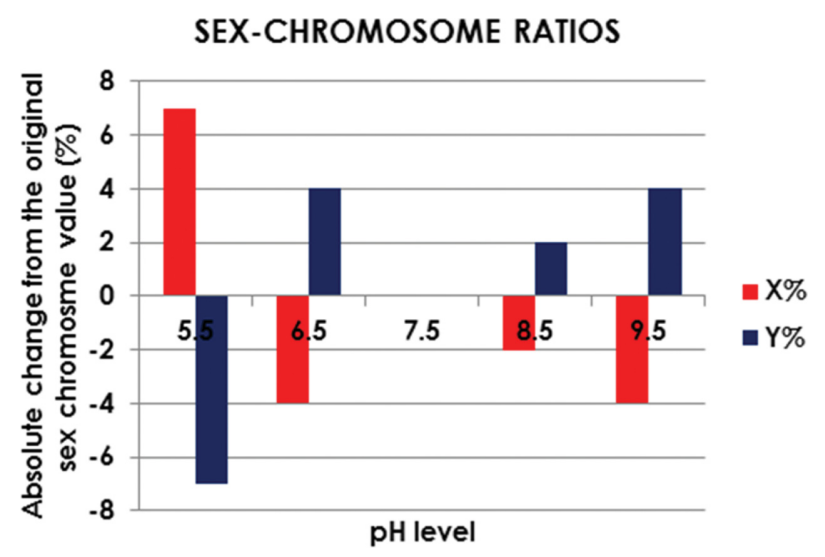

Fig. 1. Effect of $\mathrm{pH}$ on the sex-chromosome ratios in spermatozoa. 
Table 1. X-and Y-chromosome ratios in viable spermatozoa populations after exposure to different environmental conditions

\begin{tabular}{|c|c|c|}
\hline \multicolumn{3}{|c|}{ pH incubation } \\
\hline $\mathrm{pH}$ value & $\begin{array}{l}\text { X-chromosome-bearing spermatozoa } \\
\text { percentage and percentage change from } \\
\text { 'neat' sex chromosome in brackets }(\%)\end{array}$ & $\begin{array}{l}\text { Y-chromosome-bearing spermatozoa } \\
\text { percentage and percentage change from } \\
\text { 'neat' sex chromosome in brackets }(\%)\end{array}$ \\
\hline NEAT & 55 & 45 \\
\hline 5.5 & $62(\uparrow 12.7)$ & $38(\downarrow 15.5)$ \\
\hline 6.5 & $51(\uparrow 7.2)$ & $49(\uparrow 8.9)$ \\
\hline 7.5 & $55(0)$ & $45(0)$ \\
\hline 8.5 & $53(\downarrow 3.6)$ & $47(\uparrow 4.4)$ \\
\hline 9.5 & $51(\downarrow 7.2)$ & $49(\uparrow 8.9)$ \\
\hline \multicolumn{3}{|c|}{ Temperature incubation } \\
\hline Temperature & $\begin{array}{l}\text { X-chromosome-bearing spermatozoa } \\
\text { percentage and percentage change from } \\
\text { 'neat' sex chromosome in brackets }(\%)\end{array}$ & $\begin{array}{l}\text { Y-chromosome-bearing spermatozoa } \\
\text { percentage and percentage change from } \\
\text { 'neat' sex chromosome in brackets }(\%)\end{array}$ \\
\hline NEAT & 52 & 48 \\
\hline $37^{\circ} \mathrm{C}$ & $52(0)$ & $48(0)$ \\
\hline $41^{\circ} \mathrm{C}$ & $59(\uparrow 13.4)$ & $41(\downarrow 15.5)$ \\
\hline $45^{\circ} \mathrm{C}$ & $54(\uparrow 3.8)$ & $46(\downarrow 4.2)$ \\
\hline \multicolumn{3}{|c|}{ Hydrogen peroxide incubation } \\
\hline $\begin{array}{c}\mathrm{H}_{2} \mathrm{O}_{2} \\
\text { concentration }\end{array}$ & $\begin{array}{l}\text { X-chromosome-bearing spermatozoa } \\
\text { percentage and percentage change from } \\
\text { 'neat' sex chromosome in brackets }(\%)\end{array}$ & $\begin{array}{l}\text { Y-chromosome-bearing spermatozoa } \\
\text { percentage and percentage change from } \\
\text { 'neat' sex chromosome in brackets }(\%)\end{array}$ \\
\hline NEAT & 54 & 46 \\
\hline $50 \mu \mathrm{M}$ & $54(0)$ & $46(0)$ \\
\hline $750 \mu \mathrm{M}$ & $57(\uparrow 5.5)$ & $43(\downarrow 6.5)$ \\
\hline $1,000 \mu \mathrm{M}$ & $56(\uparrow 3.7)$ & $44(\downarrow 4.3)$ \\
\hline
\end{tabular}

$\uparrow$ and $\downarrow$ symbolise increase and decrease, respectively.

Percentage change from 'neat' sex-chromosome (Change from the neat value/neat value $\times 100$ ).

matozoa followed the same trend as the total and progressive motilities, indicating that the velocities reach their higher levels at $\mathrm{pH} 8.5$, while decreasing when the $\mathrm{pH}$ becomes either more acidic or more alkaline, as shown in Fig. 2C-2F.

The VCL reached its maximum at 7.5 and remained relatively constant across all $\mathrm{pH}$ tested. The VSL data indicated a peak at $\mathrm{pH} 8.5$, thereby contrasting with all the other parameters monitored in this study. There was a statistically significant difference in VSL between $\mathrm{pH} 8.5$ and 5.5 $(22.58 \pm 3.066 \mu \mathrm{m} / \mathrm{s}$ vs. $16.25 \pm 3.066 \mu \mathrm{m} / \mathrm{s}, p=0.039)$ as well as between $\mathrm{pH} 8.5$ and $6.5(22.58 \pm 3.066 \mu \mathrm{m} / \mathrm{s}$ vs. $16.17 \pm 3.066 \mu \mathrm{m} / \mathrm{s}, p=0.037)$.

When considering the linearity of movement of the spermatozoa, a peak was observed at $\mathrm{pH}$ 8.5. According to these results, there were statistically significant differences in the LIN values obtained from spermatozoa placed either at $\mathrm{pH} 8.5$ or $5.5(41.02 \pm 2.264 \%$ vs. $34.90 \pm 2.264 \%, p=$ $0.002)$, between $\mathrm{pH} 8.5$ and $6.5(41.02 \pm 2.264 \%$ vs. $35.36 \pm$ $2.264 \%, p=0.004)$, as well as between $\mathrm{pH} 8.5$ and 9.5 $(41.02 \pm 2.264 \%$ vs. $36.47 \pm 2.264 \%, p=0.017)$. Furthermore, although not statistically significant, there was a difference in the LIN observed between $\mathrm{pH} 8.5$ and 7.5 (41.02 \pm

\section{$2.264 \%$ vs. $37.77 \pm 2.264 \%, p=0.083)$.}

The STR data followed a trend that was very similar to that observed for the LIN values. The data indicated that the greatest STR values were reached at $\mathrm{pH} 8.5$, with statistically significant differences observed between $\mathrm{pH} 8.5$ and $5.5(66.89 \pm 2.759 \%$ vs. $59.25 \pm 2.759 \%, p=0.001)$ and between $\mathrm{pH} 8.5$ and $6.5(66.89 \pm 2.759 \%$ vs. $60.54 \pm 2.759 \%$, $p=0.006)$. Decreases in STR were also noted between $\mathrm{pH}$ 8.5 and $7.5(66.89 \pm 2.759 \%$ vs. $63.53 \pm 2.759 \%, p=0.132)$ and between $\mathrm{pH} 8.5$ and $9.5(66.89 \pm 2.759 \%$ vs. $62.52 \pm$ $2.759 \%, p=0.052$ ).

\section{Effect of temperature on spermatozoa.}

- Sex-chromosome ratio: The effects of increased temperatures on the sex-chromosome ratios of the spermatozoa are summarized in Table 1 and illustrated in Fig. 3. After 25 min of incubation, at a standard temperature of $37^{\circ} \mathrm{C}$, there was no change in the sex-chromosome ratio of the sample (X $52: 52$, Y $48: 48$ ). At $41^{\circ} \mathrm{C}$, there was an absolute increase of $7 \%$ in the incidence of $\mathrm{X}$-chromosomebearing spermatozoa compared to that in the sample prior to processing (52\% vs. 59\%), indicating a $13.46 \%$ increase, 

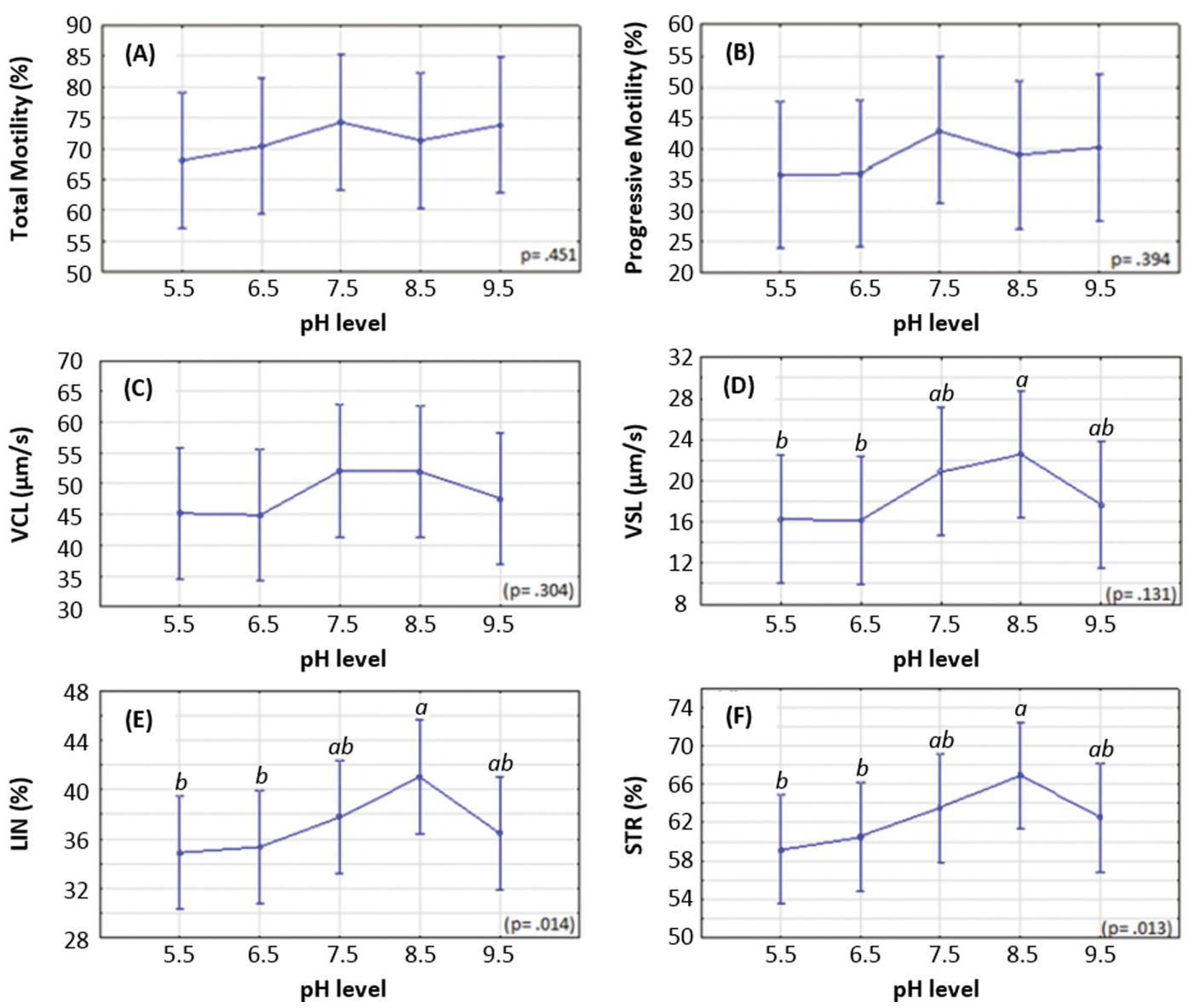

Fig. 2. Effect of pH on motility and velocity parameters of spermatozoa. (A) total motility, (B) progressive motility, (C) curvilinear velocity (VCL), (D) straight line velocity (VSL), (E) linearity (LIN), and (F) straightness (STR). Significance denoted as: a differs significantly from $\mathrm{b}$; ab does not differ significantly from $a$ or $b$.

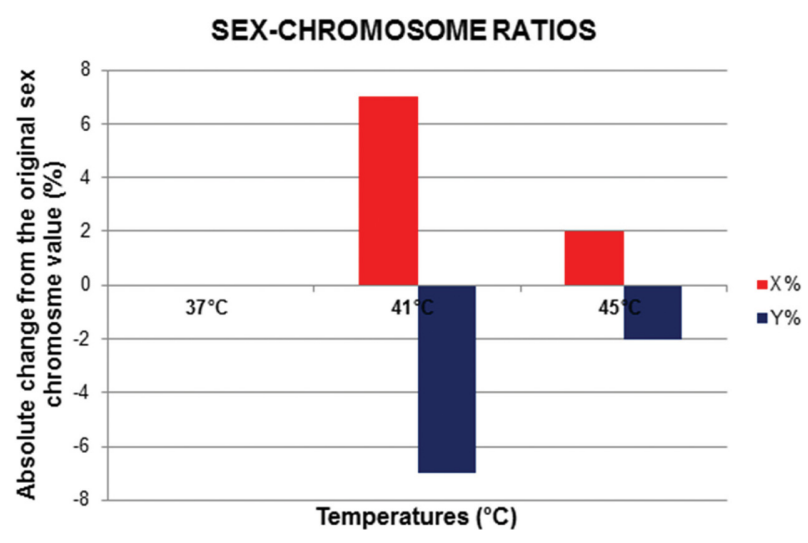

Fig. 3. Effect of temperature on sex-chromosome ratios in spermatozoa.

and at $45^{\circ} \mathrm{C}$, the incidence of $\mathrm{X}$-chromosome-bearing spermatozoa increased by $2 \%$ compared to that in the neat semen sample (52\% vs. 54\%), representing a $3.84 \%$ increase.

- Sperm motility: Fig. 4A and 4B represent the effect of temperature on the motility of the spermatozoa. The data indicated a statistically significant decrease in the percentage of motile cells between 37 and $45^{\circ} \mathrm{C}(74.55 \pm 3.883 \%$ vs. $55.53 \pm 3.883 \%, p=0.013)$. The difference in total motility between 41 and $45^{\circ} \mathrm{C}(72.28 \pm 3.883 \%$ vs. $55.53 \pm 3.883 \%, p=$ 0.022 ) was also statistically significant, as shown in Fig. 4A.

Progressive motility (Fig. 4B) followed the same trend as total motility, and declined significantly between 37 and $45^{\circ} \mathrm{C}(35.25 \pm 2.719 \%$ vs. $11.73 \pm 2.719 \%, p=0.001)$ as well as between 41 and $45^{\circ} \mathrm{C}(39.73 \pm 2.719 \%$ vs. $11.73 \pm 2.719 \%$, $p=0.0003)$.

- Sperm velocity parameters: The data obtained for the velocity parameters after incubating at different temperatures all followed the same trend, as illustrated in Fig. 4C4F. Values increased slightly as the temperature increased from 37 to $41^{\circ} \mathrm{C}$, before declining significantly as the temperature increased to $45^{\circ} \mathrm{C}$.

The curvilinear velocity increased significantly between 37 and $41^{\circ} \mathrm{C}(43.43 \pm 2.697 \mu \mathrm{m} / \mathrm{s}$ vs. $53.60 \pm 2.697 \mu \mathrm{m} / \mathrm{s}$, $p=0.037)$. There was a statistically significant decrease in VCL going from 37 to $45^{\circ} \mathrm{C}(43.43 \pm 2.697 \mu \mathrm{m} / \mathrm{s}$ vs. $26.10 \pm$ $2.697 \mu \mathrm{m} / \mathrm{s}, p=0.004$ ) as well as going from 41 to $45^{\circ} \mathrm{C}$ 

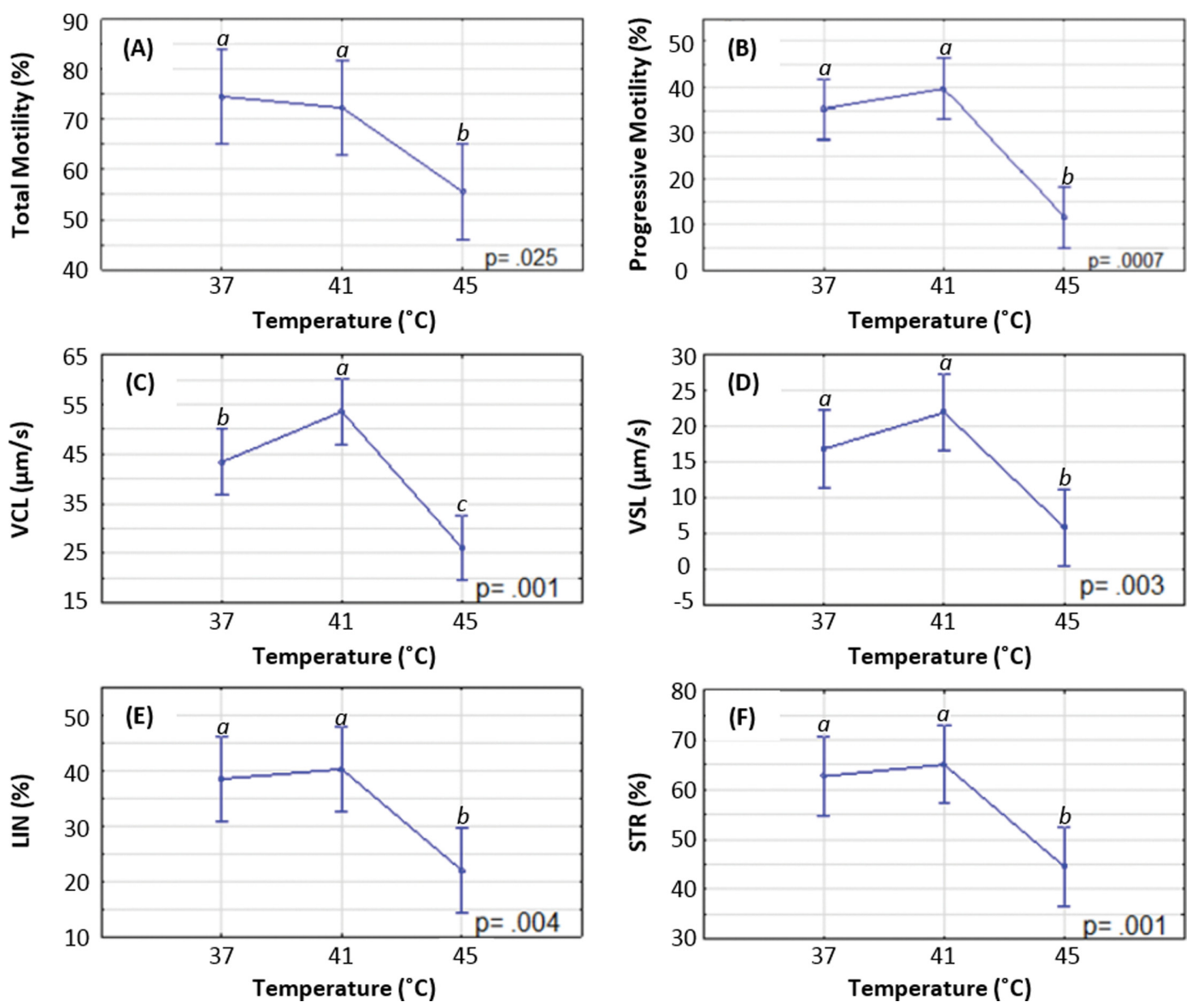

Fig. 4. Effect of temperature on motility and velocity parameters of spermatozoa. (A) total and (B) progressive motility, (C) curvilinear velocity (VCL), (D) straight line velocity (VSL), (E) linearity (LIN) and (F) straightness (STR). Significance denoted as: a differs significantly from $b$ and $c ; b$ differs significantly from $a$ and $c$.

\section{SEX-CHROMOSOMERATIOS}

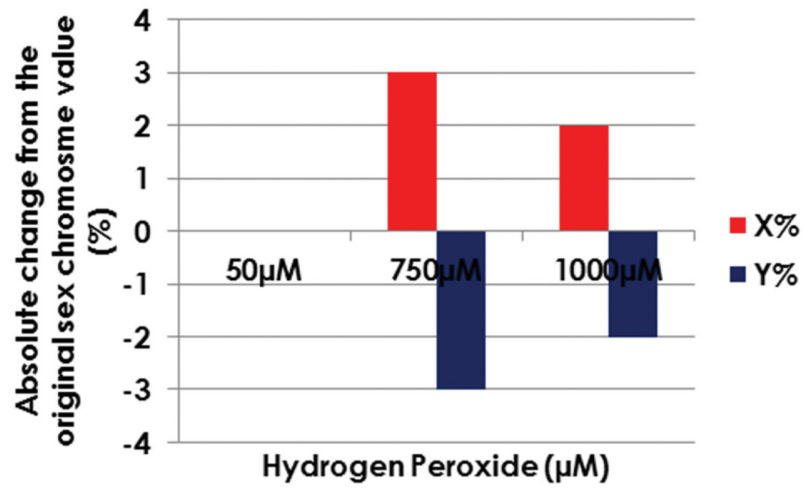

Fig. 5. Effect of hydrogen peroxide on sex-chromosome ratios in spermatozoa.

$(53.60 \pm 2.697 \mu \mathrm{m} / \mathrm{s}$ vs. $26.10 \pm 2.697 \mu \mathrm{m} / \mathrm{s}, p=0.0003)$, as shown in Fig. 4C.

The data obtained for VSL indicated a significant decrease going from 37 to $45^{\circ} \mathrm{C}(16.78 \pm 2.180 \mu \mathrm{m} / \mathrm{s}$ vs. $5.85 \pm 2.180$ $\mu \mathrm{m} / \mathrm{s}, p=0.009)$. A statistically significant decrease in VSL was also noted between temperatures of 41 and $45^{\circ} \mathrm{C}(21.85 \pm$ $2.180 \mu \mathrm{m} / \mathrm{s}$ vs. $5.85 \pm 2.180 \mu \mathrm{m} / \mathrm{s}, p=0.001)$, as shown in Fig. 4D.

The results gathered for LIN showed a significant decrease in linear movement going from 41 to $45^{\circ} \mathrm{C}(40.23 \pm 3.111 \%$ vs. $21.93 \pm 3.111 \%, p=0.004)$, and between 37 and $45^{\circ} \mathrm{C}$ $(38.45 \pm 3.111 \%$ vs. $21.93 \pm 3.111 \%, p=0.002)$. There were virtually no differences in LIN between temperatures of 37 and $41^{\circ} \mathrm{C}(38.45 \pm 3.111 \%$ vs. $40.23 \pm 3.111 \%, p=$ $0.644)$, as shown in Fig. 4E.

STR results indicated a statistically significant decrease going from 41 to $45^{\circ} \mathrm{C}(65.10 \pm 3.219 \%$ vs. $44.58 \pm 3.219 \%$, $p=0.0006)$ and 37 to $45^{\circ} \mathrm{C}(62.73 \pm 3.219 \%$ vs. $44.58 \pm$ $3.219 \%, p=0.001)$. There was no significant difference in STR between temperatures of 37 and $41{ }^{\circ} \mathrm{C}(62.73 \pm 3.219 \%$ vs. $65.10 \pm 3.219 \%, p=0.477$ ), as shown in Fig. $4 \mathrm{~F}$.

\section{Effect of $\mathrm{H}_{2} \mathrm{O}_{2}$ on spermatozoa.}

- Sex-chromosome ratio: Upon exposure to $\mathrm{H}_{2} \mathrm{O}_{2}$ at $50 \mu \mathrm{M}$, there was no change in the sex-chromosome ratios 
compared to that in the unprocessed semen samples, as shown in Fig. 5. At a concentration of $750 \mu \mathrm{M}$, an absolute increase of $3 \%$ was observed in the incidence of X-chromosome-bearing spermatozoa ( $54 \%$ vs. $57 \%$ ), translating into a percentage increase of $5.5 \%$. Exposure of the spermatozoa to $1,000 \mu \mathrm{M} \mathrm{H}_{2} \mathrm{O}_{2}$ still generated enriched X-chromosome-bearing spermatozoa samples, but to a lower extent, with an absolute increase of $2 \%$ compared to the neat semen $(54 \%$ vs. $56 \%)$, which translates into a percentage increase of $3.7 \%$.

- Sperm motility: The effect of $\mathrm{H}_{2} \mathrm{O}_{2}$ on motility parameters of the spermatozoa are shown in Fig. 6. Both total (Fig. 6A) and progressive motilities (Fig. 6B) declined significantly between exposures to 50 and $750 \mu \mathrm{M}$ (total motility, $79.15 \pm 9.047 \%$ vs. $55.65 \pm 9.047 \%, p=0.016$; progressive motility, $53.63 \pm 7.697 \%$ vs. $22.23 \pm 7.697 \%, p=0.021)$ and to 50 and $1,000 \mu \mathrm{M}$ (total motility, $79.15 \pm 9.047 \%$ vs. $59.63 \pm 9.047 \%, p=0.033$; progressive motility, $53.63 \pm$ $7.697 \%$ vs. $16.63 \pm 7.697 \%, p=0.011)$. There were no significant differences in any of the motility parameters between exposures to either 750 or $1,000 \mu \mathrm{M}$.
- Sperm velocity parameters: Exposure of spermatozoa to $\mathrm{H}_{2} \mathrm{O}_{2}$ also compromised the velocity parameters of the cells (Fig. 6C-6F). The same trend could be observed throughout all the data: velocity decreased steadily and significantly when going from an exposure to a low $\mathrm{H}_{2} \mathrm{O}_{2}$ concentration of $50 \mu \mathrm{M}$ toward higher concentrations of $750 \mu \mathrm{M}$ and $1,000 \mu \mathrm{M}$.

The VCL data indicated significant decreases going from a 50 to a $750 \mu \mathrm{M} \mathrm{H}_{2} \mathrm{O}_{2}$ exposure $(52.75 \pm 4.427 \mu \mathrm{m} / \mathrm{s}$ vs. $35.23 \mu \mathrm{m} / \mathrm{s}, p=0.031$ ), as well as from 50 to $1,000 \mu \mathrm{M}$ $(52.75 \pm 4.427 \mu \mathrm{m} / \mathrm{s}$ vs. $25.05 \mu \mathrm{m} / \mathrm{s}, p=0.004)$, as shown in Fig. 6C.

VSL was affected similarly, with a significant decrease upon incubation in either 50 or $750 \mu \mathrm{M} \mathrm{H}_{2} \mathrm{O}_{2}(18.85 \pm$ $2.353 \mu \mathrm{m} / \mathrm{s}$ vs. $8.30 \pm 2.353 \mu \mathrm{m} / \mathrm{s}, p=0.019)$ and between 50 and $1,000 \mu \mathrm{M} \mathrm{H} \mathrm{H}_{2} \mathrm{O}_{2}(18.85 \pm 2.353 \mu \mathrm{m} / \mathrm{s}$ vs. $4.58 \pm 2.353$ $\mu \mathrm{m} / \mathrm{s}, p=0.005)$, as shown in Fig. 6D.

The results obtained for LIN and STR indicated a significant decrease going from 50 to $1,000 \mu \mathrm{M} \mathrm{H}_{2} \mathrm{O}_{2}$ incubation (LIN, $35.68 \pm 4.017 \%$ vs. $16.40 \pm 4.017 \%, p=0.013$; STR, $58.60 \pm 4.304$ vs. $31.35 \pm 4.304, p=0.004$ ), while STR also
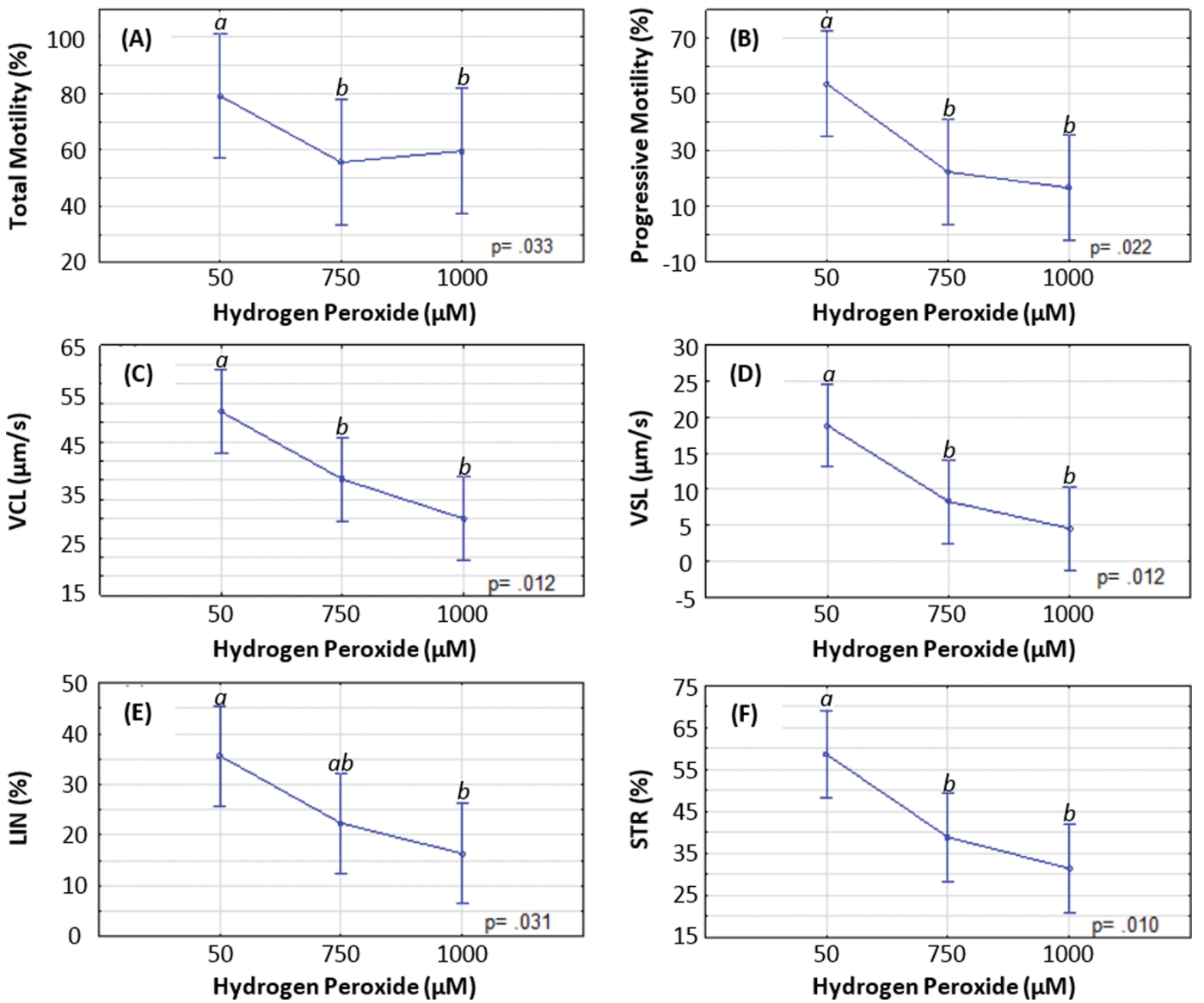

Fig. 6. Effect of hydrogen peroxide on motility and velocity parameters of spermatozoa. (A) total motility, (B) progressive motility, (C) curvilinear velocity (VCL), (D) straight line velocity (VSL), (E) linearity (LIN), and (F) straightness (STR). Significance denoted as: a differs significantly from b; ab does not differ significantly from a or b. 
decreased significantly going from 50 to $750 \mu \mathrm{M} \mathrm{H} \mathrm{H}_{2} \mathrm{O}_{2}$ $(58.60 \pm 4.304 \%$ vs. $38.83 \pm 4.304 \%, p=0.018)$, as shown in Figs. $6 \mathrm{E}$ and $6 \mathrm{~F}$.

\section{DISCUSSION}

Current methods employed to perform sperm separation are based on the hypothetical existence of fundamental and physiological differences between X- and Y-chromosomebearing spermatozoa, as well as on the assumption that these differences are significant enough to enable separation. In the present study, the exposure of sperm samples to various $\mathrm{pH}$ and temperature ranges, as well as $\mathrm{H}_{2} \mathrm{O}_{2}$ concentrations, allowed for enrichment of the viable sperm population with X-chromosome-bearing cells. It was found that at an acidic $\mathrm{pH}$ (5.5), more X-chromosome-bearing spermatozoa were able to thrive, while more physiological and alkaline $\mathrm{pH}$ were more favorable for the survival of Y-chromosome-bearing spermatozoa. This may indicate that the larger size of the X-chromosome-bearing spermatozoa, compared to that of the Y-chromosome-bearing spermatozoa, may allow for an increased cytoplasmic volume (8), which in turn could lead to higher levels of intracellular proteins and phosphates that are able to act as intracellular buffering components, ultimately enabling the X-spermatozoa to survive in acidic $\mathrm{pH}$ environments. However, the increases in Y-chromosome-bearing spermatozoa at $\mathrm{pH} 8.5$ and 9.5 indicate the existence of optimal $\mathrm{pH}$ ranges for the isolation of Y-spermatozoa. Interestingly, all the neat samples had higher ratios of X- to with Y-chromosome-bearing cells. This may be due to the fact that X-chromosome-bearing cells are more abundant and viable within the epididymis due to their robust nature.

The motility data obtained on X- and Y-chromosome-bearing spermatozoa enriched samples suggest that the samples with higher counts of Y-chromosome-bearing spermatozoa (at $\mathrm{pH} 8.5$ and 9.5) present increased percentages of total and progressively motile spermatozoa. The results gathered for the velocity parameters indicate that a $\mathrm{pH}$ of 8.5 yields the fastest swimming post-processed spermatozoa in terms of VSL, LIN, and STR. This suggests that upon deposition into the vaginal regions after ejaculation, where $\mathrm{pH}$ often reaches levels below 4, Y-chromosome-bearing spermatozoa might not be able to remain viable for long enough to reach the cervical os. The decrease in $\mathrm{pH}$ is usually due to the estrogen surge occurring just prior to ovulation, previously described in the female reproductive tract (17), which favors the survival of X-chromosome-bearing spermatozoa. This is in accordance with Shettle's method of sex preselection, which states that in order to conceive a girl, intercourse should take place 2-3 days prior to ovulation (6).

This study also showed that the linear progression was significantly higher at $\mathrm{pH} 8.5$, at which Y-chromosomebearing spermatozoa were more numerous, thereby suggest- ing that after ovulation, as the $\mathrm{pH}$ in the female reproductive tract rises, Y-chromosome-bearing spermatozoa will be able to survive better. This increased motility indicates that Y-chromosome-bearing spermatozoa will reach and fertilize the oocyte earlier if intercourse occurs a day after ovulation. Higher numbers of X-chromosome-bearing spermatozoa were observed upon exposure to increased temperatures in this study. The control temperature of $37^{\circ} \mathrm{C}$ had no influence on sex-chromosome ratios, but when the temperature was elevated to $41^{\circ} \mathrm{C}$, there was a considerable increase in the incidence of X-chromosome-bearing spermatozoa in the sample. This increase can be attributed to the Y-chromosome-bearing spermatozoa not being able to withstand this rise in temperature due to their fragile nature. At $45^{\circ} \mathrm{C}$, the $\mathrm{X}$-chromosome-bearing spermatozoa were still more numerous than the Y-Chromosome ones, although the difference was not as marked as when incubated at $41^{\circ} \mathrm{C}$. Accordingly, the percentages of total and progressively motile cells decreased significantly at $45^{\circ} \mathrm{C}$. At $41^{\circ} \mathrm{C}$, the motility of the spermatozoa improved, especially the velocity parameters, probably due to the spermatozoa starting to become hyperactivated at this temperature.

The effect of $\mathrm{H}_{2} \mathrm{O}_{2}$ on the sex-chromosome ratio followed the same trend as the one observed during the temperature incubation experiments, with X-chromosome-bearing spermatozoa numbers increasing in both the moderate $(750 \mu \mathrm{M})$ and high $(1,000 \mu \mathrm{M}) \mathrm{H}_{2} \mathrm{O}_{2}$ fractions. There were no changes in sex-chromosome ratio or viability of the spermatozoa after incubation with $50 \mu \mathrm{M}$ of $\mathrm{H}_{2} \mathrm{O}_{2}$. The ability of the Xchromosome-bearing spermatozoa to survive from exposures to $750 \mu \mathrm{M}$ and $1,000 \mu \mathrm{M}$ of $\mathrm{H}_{2} \mathrm{O}_{2}$, suggests that these cells may have more sophisticated intracellular protection mechanisms against hostile environments, since their chromatin content is about $3 \%$ denser. It is hypothesized that an increased intracellular storage of antioxidants may take place, or that the membranes of the X-chromosome-bearing spermatozoa might be more resistant to the external environment, which could be resulting from differences in surface charges and/or surface protein properties between the X- and Y-chromosome-bearing spermatozoa. Motility results (total, progressive, and velocity parameters) show a significant decrease in the measured parameters when exposed to $750 \mu \mathrm{M}$ and $1,000 \mu \mathrm{M}$, and the decrease in Ychromosome-bearing spermatozoa within the samples is possibly due to an overall increase in intracellular ROS level. However, incubation with $50 \mu \mathrm{M} \mathrm{H}_{2} \mathrm{O}_{2}$ showed beneficial effects on the motility parameters of the spermatozoa, especially in terms of velocity-related parameters. The overlapping observations made after exposures to either $750 \mu \mathrm{M}$ or $1,000 \mu \mathrm{M} \mathrm{H}_{2} \mathrm{O}_{2}$ concentrations indicated similar deleterious effects produced by these elevated concentrations on the motility of the spermatozoa. The results of this study indicate that the differences in viability between $\mathrm{X}$ - and Ychromosome-bearing spermatozoa after exposure to differ- 
ent environmental conditions represent a real potential toward improving the chances of selecting a preferred gender during conception.

This study confirmed once again the existence of differences in viability between $\mathrm{X}$ - and Y-chromosome-bearing spermatozoa, indicating optimal enrichment of X-chromosome-bearing spermatozoa through incubation in acidic media or at increased temperatures, which could represent an interest in the field of ART. The potential to increase the ratio of X-chromosome-bearing spermatozoa even further by combining these methods requires further investigation.

\section{ACKNOWLEDGMENTS}

The authors are grateful to the Faculty of Medicine and Health Sciences, University of Stellenbosch, for the postdoctoral fellowship awarded to the first author, and also to the Harry Crossley Foundation (South Africa) for funding this research.

\section{CONFLICT OF INTEREST}

None declared by all authors.

Received June 5, 2017; Revised July 6, 2017; Accepted July 17,2017

\section{REFERENCES}

1. Gray, R.H. (1991) Natural family planning and gender selection: fact or fiction? Am. J. Obstet. Gynecol., 165, 1982-1984.

2. Wilcox, A.J., Weinberg, C.R. and Baird, D.D. (1995) Timing of sexual intercourse in relation to ovulation. Effects on the probability of conception, survival of the pregnancy, and sex of the baby. N. Engl. J. Med., 333, 1517-1521.

3. Jaiyesimi, E.O. and Jaiyesimi, R.A.K. (2004) Sex selection. Sexual Health Matters, 5, 27-29.

4. Nie, J.B. (2011) Non-medical sex-selective abortion in China: ethical and public policy issues in the context of 40 million missing females. Br. Med. Bull., 98, 7-20.

5. Dawson, K. and Trounson, A. (1996) Ethics of sex selection for family balancing. Why balance families? Hum. Reprod.,
11, 2577-2578.

6. Shettles, L.B. and Rorvik, D.M. (2006) How To Choose The Sex Of Your Baby: Fully Revised And Updated (Rev Upd edition). Broadway.

7. Gledhill, B.L. (1988) Selection and separation of X- and Ychromosome-bearing mammalian sperm. Gamete Res., 20, 377-395.

8. Cui, K.H. (1997) Size differences between human X and Y spermatozoa and prefertilization diagnosis. Mol. Hum. Reprod., 3, 61-67.

9. Gledhill, B.L. and Edwards, R.G. (1993) Can spermatozoa be typed? in Preconception And Preimplantation Diagnosis Of Human Genetic Disease (Edwards, R.G. Ed.). Cambridge University Press, Cambridge, UK, pp. 203-231.

10. Johnson, L.A. (1994) Isolation of X- and V-bearing sperm for sex preselection in Oxford Reviews of Reproductive Biology, Vol. 16 (Charlton, H.M. Ed.). Oxford University Press, Oxford, UK, pp. 303-326.

11. Cui, K.H. and Matthews, C.D. (1993) X larger than Y. Nature, 366, 117-118.

12. Flaherty, S.P. and Matthews, C.D. (1996) Application of modern molecular techniques to evaluate sperm sex selection methods. Mol. Hum. Reprod., 2, 937-42.

13. Jeon, H.L., Yi, J.S., Kim, T.S., Oh, Y., Lee, H.J., Lee, M., Bang, J.S., Ko, K., Ahn, I.Y., Ko, K., Kim, J., Park, H.K., Lee, J.K. and Sohn, S.J. (2017) Development of a test method for the evaluation of DNA damage in mouse spermatogonial stem cells. Toxicol. Res., 33, 107-118.

14. Ahmad, G., Agarwal, A., Esteves, S.C., Sharma, R., Almasry, M., Al-Gonaim, A., AlHayaza, G., Singh, N., Al Kattan, L., Sannaa, W.M. and Sabanegh, E. (2017) Ascorbic acid reduces redox potential in human spermatozoa subjected to heatinduced oxidative stress. Andrologia, doi: 10.1111/and.12773 [Epub ahead of print].

15. Mesa, A.M., Roberson, R.L., Chun, R.I. and Mortensen, C.J. (2017) Stallion semen incubated with hydrogen peroxide decreased DNA fragmentation as measured by the TUNEL assay. J. Equine Vet. Sci., 49, 81-86.

16. World Health Organization (2010) WHO Laboratory Manual For The Examination And Processing Of Human Semen. World Health Organization.

17. Hassan, D.A. (2005) Separation Techniques for $X$ and $Y$ Chromosome Bearing Human Spermatozoa (Doctoral dissertation). Tshwane University of Technology. 